
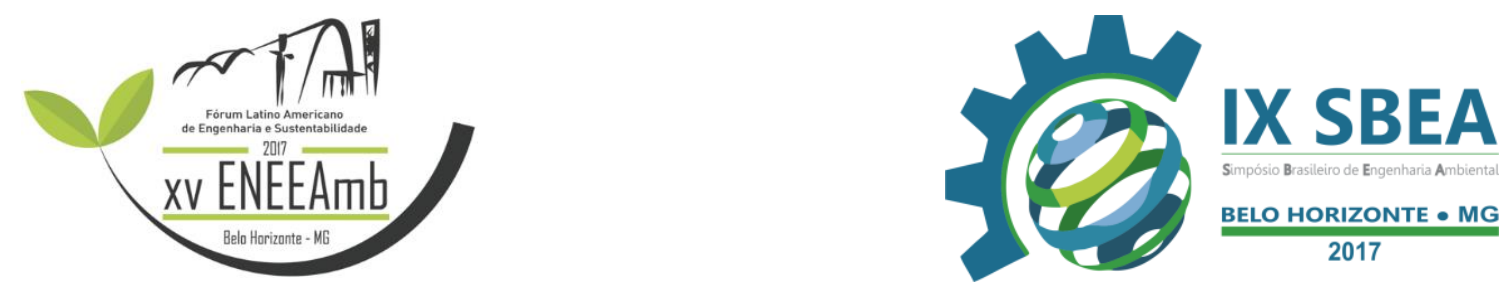

ÁREA TEMÁTICA: RESÍDUOS SÓLIDOS

\title{
ANÁLISE QUALITATIVA DO GERENCIAMENTO DE RESÍDUOS DE SERVIÇO DE SAÚDE DO HOSPITAL REGIONAL PÚBLICO DO LESTE, PARAGOMINAS-PA.
}

Lucimar Costa Pereira - lu.costa0708@gmail.com

Universidade do Estado do Pará

Lorena Saraiva Viana - lorenaengamb20@gmail.com

Universidade do Estado do Pará

Maria Renata da Rocha Xavier - renatarochax@hotamail.com

Universidade do Estado do Pará

Maycon Viana Balbino - maycon.lbino@hotmail.com

Universidade do Estado do Pará

Nayara do Socorro Nascimento Farias-nayarafarias@outlook.com

Universidade do Estado do Pará

Mateus Henrique Trajano Brasil - matheusbrasi186@hotmail.com

Universidade do Estado do Pará 

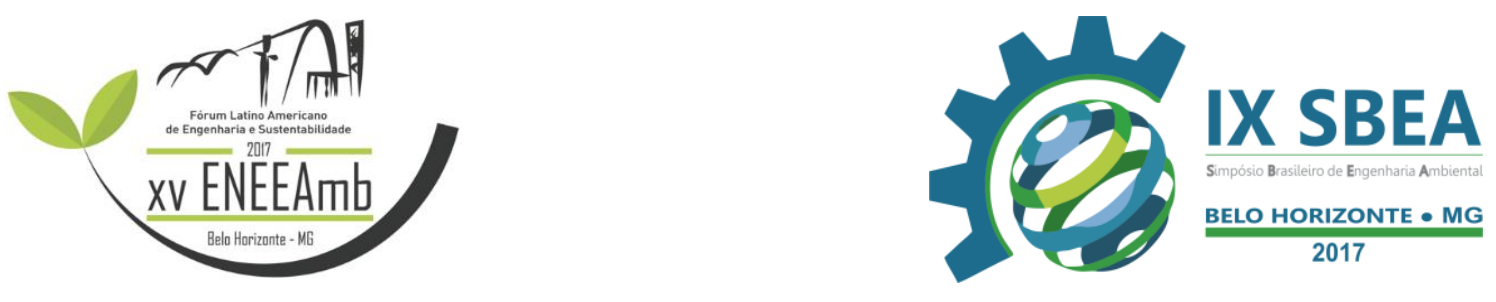

\section{RESUMO}

O avanço tecnológico provocou aumento na produção de bens de consumo duráveis e não duráveis, exigindo exploração constante dos recursos naturais, consequentemente provocando a formação de elevada quantidade de resíduos sólidos. $\mathrm{O}$ presente trabalho objetivou verificar in situ, a qualidade do Gerenciamento de Resíduos de serviço de saúde do Hospital Regional Público do Leste, localizado no município de Paragominas-PA, em consonância com a Resolução da Diretoria Colegiada (RDC) n. 306:2004 (BRASIL, 2004) que trata da melhor forma de gerenciamento dos resíduos de serviços de saúde. A metodologia empregada foi observativa, sistemática, direta, qualitativa, in situ, com aplicação de um formulário aberto e associada a levantamento de dados documentais com recorte temporário compreendido entre 2003 a 2016.

Para complemento desta foi aplicado um formulário aberto com questões relacionadas à gestão de resíduos de serviço de saúde. A Unidade de saúde possui um Plano de Gerenciamento de Resíduos de Serviço de Saúde (PGRSS). Os resíduos são coletados por funcionários treinados, utilizando equipamentos de proteção individual (EPI). Os resíduos coletados são: infectantes, material reciclável e orgânico.

O material infectante é transportado duas vezes na semana e tratado por uma empresa terceirizada denominada "Preserve, coleta de resíduos". Estes resíduos são incinerados e, posteriormente analisados quimicamente com o intuito de verificar-se o grau de periculosidade das cinzas. Os materiais que apresentarem componentes perigosos são encaminhados para a cidade de Brasília- DF e os que não representarem riscos são transportados para o aterro sanitário da própria empresa. Os resíduos recicláveis e orgânicos são retirados externamente por veículos da prefeitura.

A Unidade de Saúde cumpre com as etapas de coleta, segregação, acondicionamento, transporte interno, transporte externo e destinação final) exigidas pelo Plano de Gerenciamento de Resíduos de Serviço de Saúde, estando em consonância com a Resolução da Diretoria Colegiada (RDC) n. 306:2004.

Palavras-chave: Resoluções, Material, Coleta. 

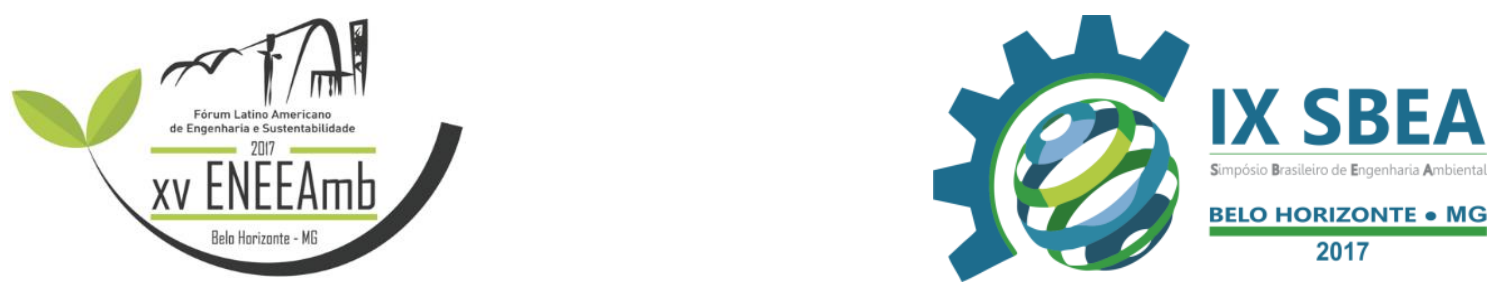

\section{INTRODUÇÃO}

A palavra resíduo, constituinte do termo "resíduos sólidos" origina-se do latim residuu, o que significa sobra de determinada substância e a palavra sólido é integrado para diferenciá-los de gases e líquidos. O termo resíduos sólidos ainda é definido pela NBR ABNT 10.004:2004 como "resíduos nos estados sólido e semissólido, que resultam de atividades de origem industrial, doméstica, hospitalar, comercial, agrícola, de serviços e de varrição" (ABNT, 2004).

Nesta classificação, destacam-se os resíduos de serviço de saúde (RSS) que são denominados como especiais, devido às suas características de periculosidade (ABNT, 2004). De acordo com Schneider, et al., (2004), os RSS são resíduos oriundos das atividades desenvolvidas por estabelecimentos prestadores de serviços de saúde, compreendendo aqueles provenientes de diversas fontes potencialmente geradoras, tais como hospitais, clínicas médicas, veterinárias, odontológicas, farmácias, ambulatórios, postos de saúde, laboratórios de análises clínicas, de alimento, de pesquisa, consultórios médicos e odontológicos, empresas de biotecnologia, casas de repouso e casas funerárias.

A presença dos RSS no meio ambiente representa grave ameaça a qualidade do mesmo, assim como representa risco a saúde humana, necessitando dessa forma de um Gerenciamento correto de resíduos de serviço de saúde. O gerenciamento inadequado de RSS pode ter impactos diretos e indiretos em equipes de saúde, em pacientes e em todo ambiente hospitalar, com risco de transmissão de doenças, tais como cólera, desinteria, infecção de pele, hepatite e outras (MOREIRA, et al., 2015).

Como exigência legal, o Plano de Gerenciamento de Resíduos de serviço de saúde (PGRSS) deve ser elaborado de acordo com a Resolução da Diretoria Colegiada (RDC) n. 306:2004 da Agência Nacional de Vigilância Sanitária (ANVISA) e a Resolução n. 358:2005 do Conselho Nacional do Meio Ambiente (CONAMA). O principal objetivo do Plano de Gerenciamento é regular as ações dos profissionais, padronizando a forma de lidar com os resíduos, desde a geração até a destinação final (SCHNEIDER, et al., 2013).

O PGRSS tem como finalidade ainda, minimizar a geração, potencializar a reciclagem, evitar a prática de segregação incorreta e, como consequência reduzir custos 

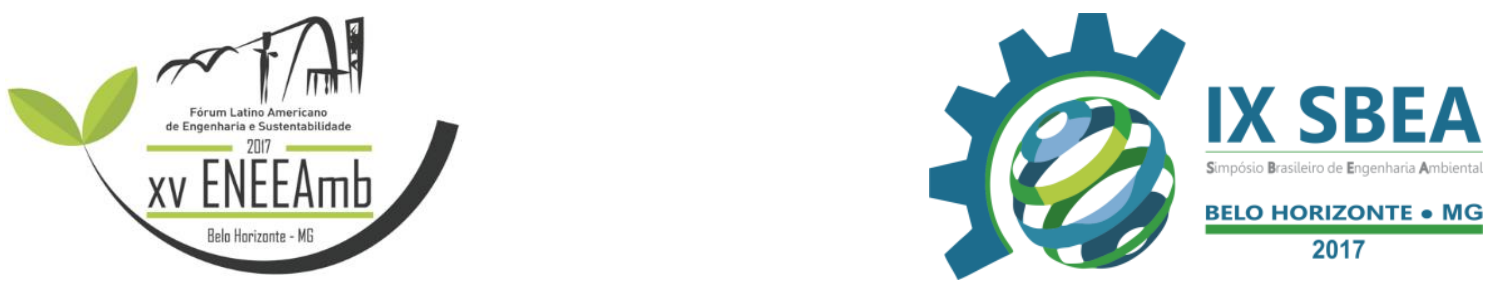

com o tratamento, assim como evitar riscos ambientais e à saúde em ambiente interno e externo das unidades geradoras. Em ambiente intra-hospitalares correm risco, os profissionais, higienizadores e pacientes e extra-hospitalar, o pessoal envolvido com a coleta externa, tratamento e disposição final, além de catadores e recicladores) (ANVISA, 2004).

O presente trabalho objetivou verificar in situ, a qualidade do Gerenciamento de Resíduos de serviço de saúde do Hospital Regional Público do Leste, localizado no município de Paragominas-PA, em consonância com a Resolução da Diretoria Colegiada (RDC) n. 306:2004 (BRASIL, 2004) que trata da melhor forma de gerenciamento dos resíduos de serviços de saúde.

\section{METODOLOGIA}

\subsection{FISIOGRAFIA DO MUNICÍPIO DE LOCALIZAÇÃO DO HOSPITAL}

O município de Paragominas, fundado em 1965, está localizado na mesorregião do nordeste paraense e ocupa uma extensão territorial de 19.330 quilômetros quadrados. O referido município sustenta sua economia através do desenvolvimento de atividades econômicas como criação de gado bovino, exploração de madeira, manejo florestal, reflorestamento, cultivo de soja (e outros grãos) e mineração de bauxita (PINTO et al., 2009).

O clima característico é do tipo mesotérmico e úmido, apresenta uma temperatura média em torno de $25^{\circ} \mathrm{C}$ e o índice pluviométrico encontra-se com valores entre 2250 mm a $2500 \mathrm{~mm}$ anuais (MARTINS, et al., 2013). A vegetação originária do município era composta por florestas densas, porém, com a progressão da agropecuária, foram reduzidas drasticamente, dando lugar a matas secundárias denominadas de capoeira (IDESP, 2014).

\section{2 ÁREA DE ESTUDO}

A pesquisa foi realizada no Hospital Regional Público do Leste, localizado no bairro Nova Conquista, Paragominas-PA (Figura 1). 

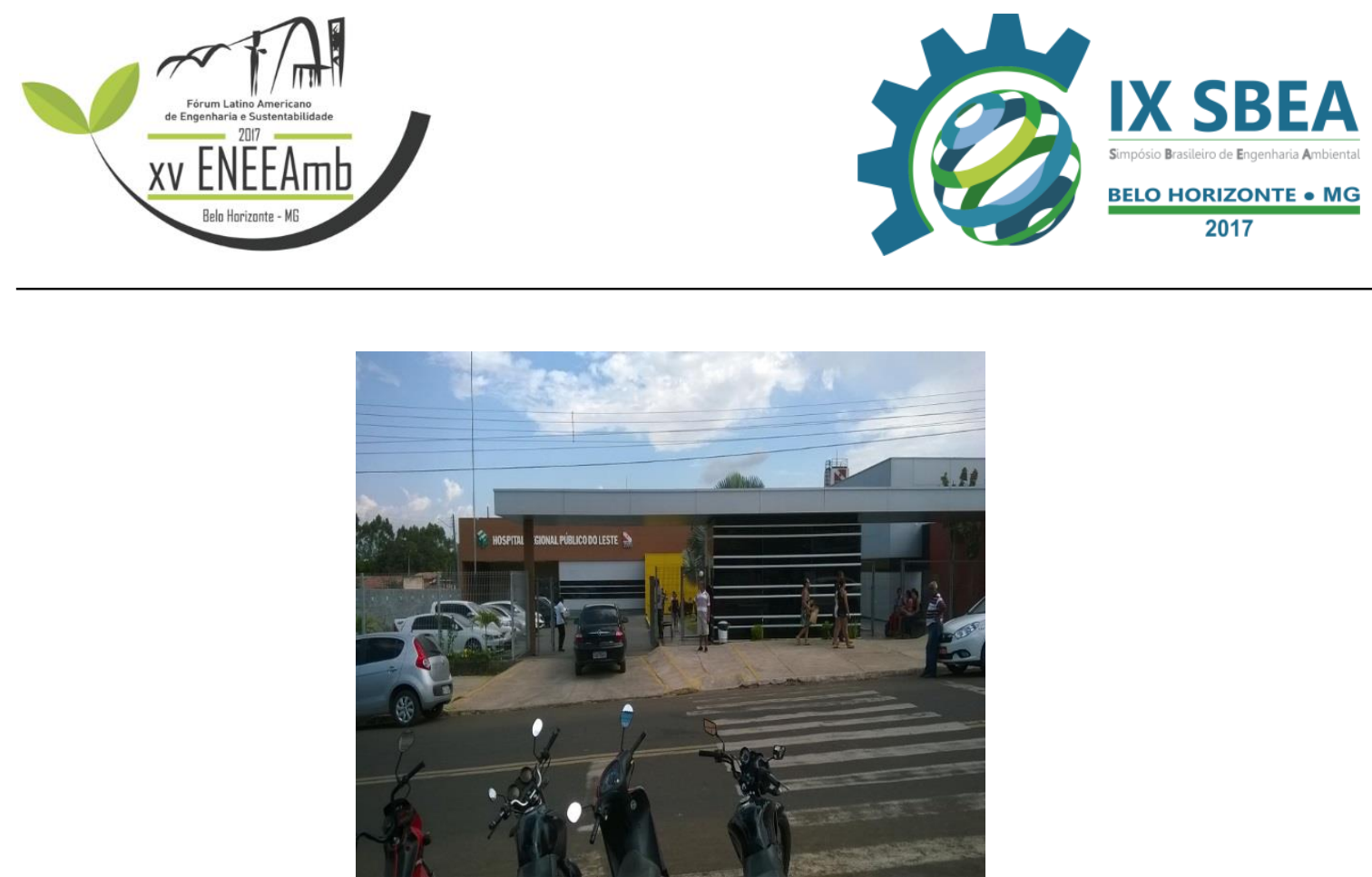

Figura 1: visão frontal do Hospital Regional do município de Paragominas-Pará

O Hospital Regional é constituído, internamente, por seis salas de consulta, quatro salas cirúrgicas, quatro postos de enfermagem, uma sala de curativos, uma sala de pronto atendimento, um laboratório de análise clínica, vinte leitos, doze enfermarias para internação, quatro aprazamentos, uma sala de gesso, três salas de radiologia/tomografia/raios $\mathrm{X}$, quatorze salas administrativas, duas lavanderias e uma cozinha.

A metodologia utilizada foi do tipo observativa, sistemática, direta, in situ, com aplicação de um formulário aberto e associada a levantamento de dados documentais com recorte temporário compreendido entre 2003 a 2016.

\section{RESULTADOS E DISCUSSÃO}

O Hospital Regional Público do Leste conta com um Plano de Gerenciamento de Resíduos de Serviço de Saúde (PGRSS). As etapas básicas (coleta, separação, transporte interno e armazenamento temporário) constituintes do PGRSS e estabelecidas pela RESOLUÇÃO RDC n 306:2004 são cumpridas pelo hospital.

Uma das etapas do gerenciamento de resíduos - acondicionamento temporário pôde ser verificada no momento da visita, haja vista que no horário, os funcionários do hospital estavam realizando o trabalho de deposição dos materiais coletados nas salas destinadas para a etapa. A praticidade de todas as etapas é apresentada a seguir.

A coleta dos resíduos é realizada duas vezes ao dia, nos períodos matutino e 

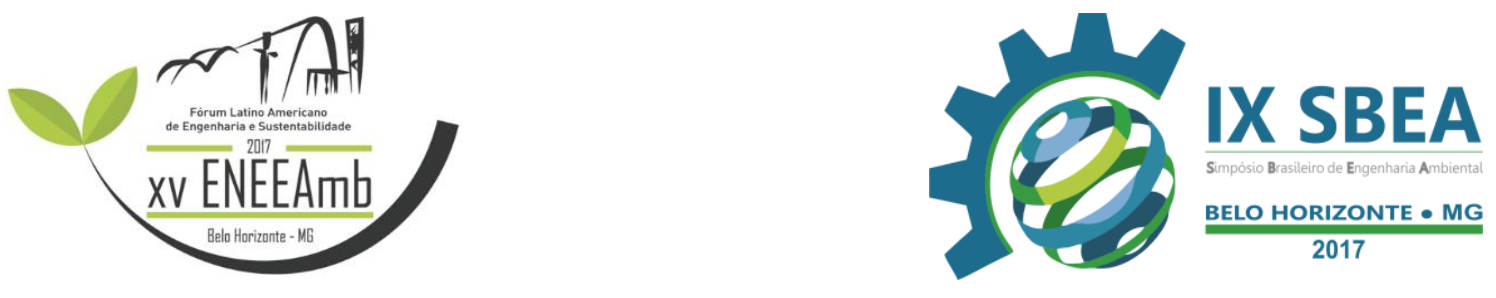

vespertino, com a utilização de conteiners de 300 L, contendo sacos descartáveis pretos, que recebem identificação quanto ao material contido no mesmo, o que caracteriza-se como cumprimento da Resolução RDC $n^{\circ} 306$, que determina no capítulo III, subitem 1.3.1, a necessidade de "identificação dos sacos de acondicionamento, nos recipientes de coleta interna e externa, nos recipientes de transporte interno e externo, e nos locais de armazenamento, em local de fácil visualização". São utilizados quatro conteiners durante a coleta para o processo de segregação e transporte dos resíduos infectantes, comuns e orgânico e coleta de roupas para lavagem (Figura 2).

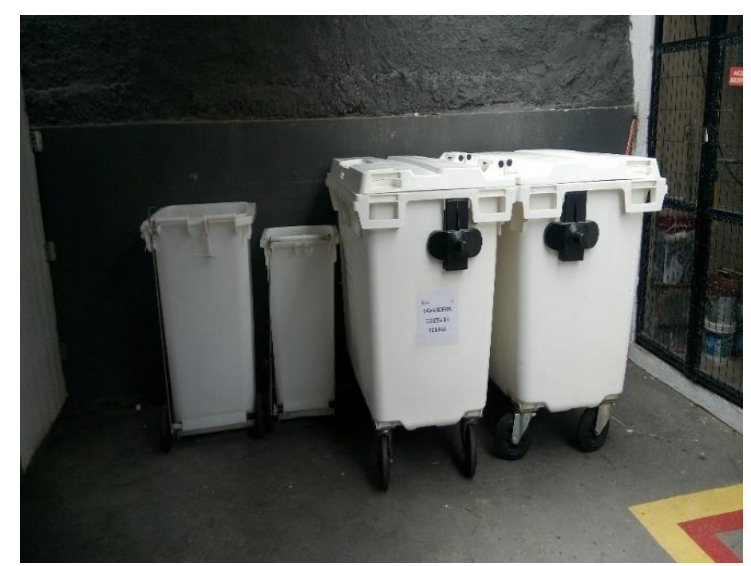

Figura 2: Conteiners utilizados para coleta e transporte dos resíduos do serviço de saúde no Hospital

Após cada coleta, os contêineres são submetidos a lavagem, respeitando a determinação do subitem 1.2.2, do capítulo III da Resolução RDC citada anteriormente, onde verifica-se que "Os sacos devem estar contidos em recipientes de material lavável, resistente à punctura, ruptura e vazamento".

Após o processo de segregação, os resíduos são transportados para as salas de armazenamento temporário. Estas apresentam características físicas em concordância com o subitem 1.5.2 do capítulo III da Resolução RDC $\mathrm{n}^{\circ} 306$, onde verifica-se a determinação de que "a sala para guarda de recipientes de transporte interno de resíduos deve ter pisos e paredes lisas e laváveis, sendo o piso ainda resistente ao tráfego dos recipientes coletores" (Figura 3). 

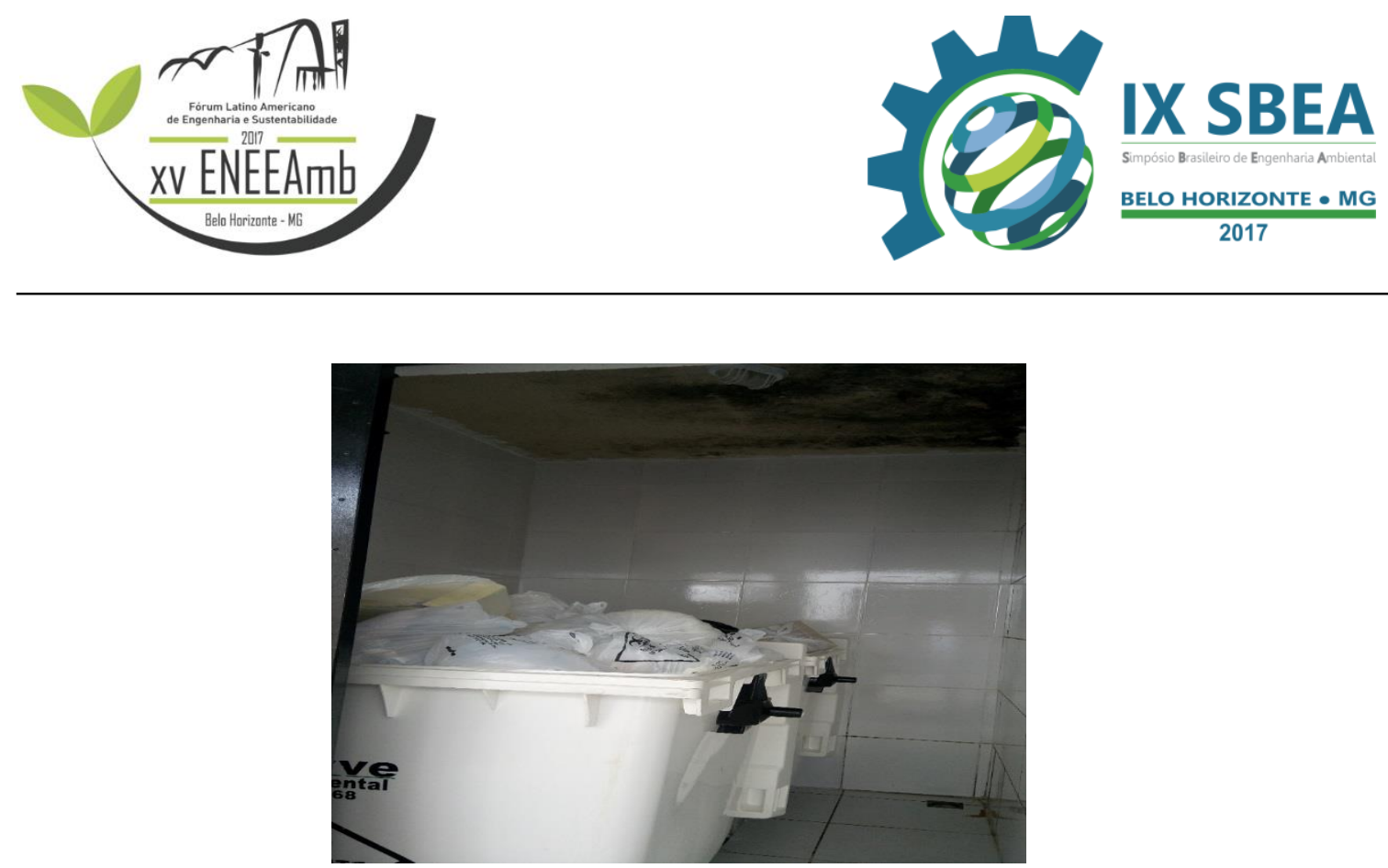

Figura 3: sala de armazenamento temporário de resíduos do Hospital

São utilizadas três salas com dimensões de $2 \mathrm{~m}^{2}$ cada. Estas são destinadas ao armazenamento de resíduos infectante, comum e orgânico. Tais locais apresentam identificação do material contido em seus interiores, nas portas de acesso (Figura 4).

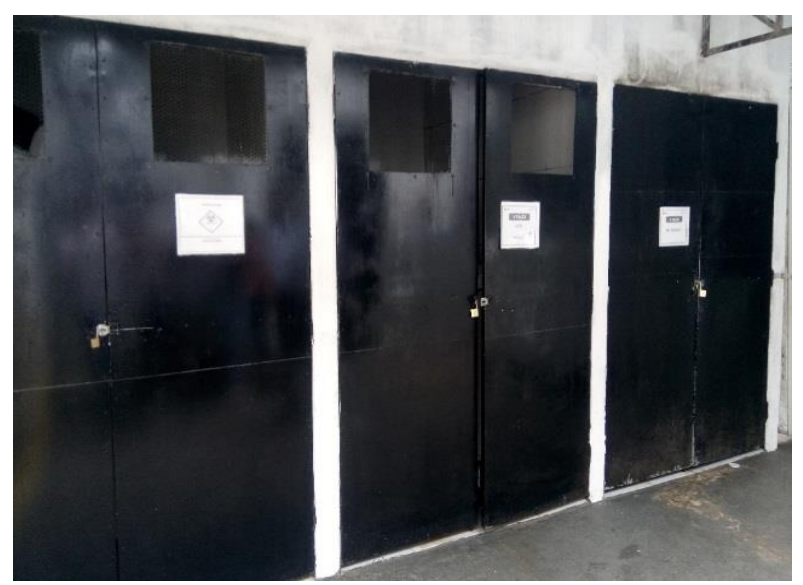

Figura 4: salas para armazenamento temporário de resíduos do Hospital

Os resíduos infectantes ficam armazenados por um período médio de dois dias, haja vista que, o transporte externo dos mesmos é realizado durante duas vezes na semana. Estes, previamente separados em caixas e sacos de acordo o grau de periculosidade, são transportados por uma empresa terceirizada denominada "Preserve, coleta de Resíduos", com sede no município de Tomé-Açu-Pará, contratada pelo Hospital para a realização do transporte, tratamento e destinação final dos resíduos infectantes.

O material infectante transportado pela empresa terceirizada passa pelo processo 

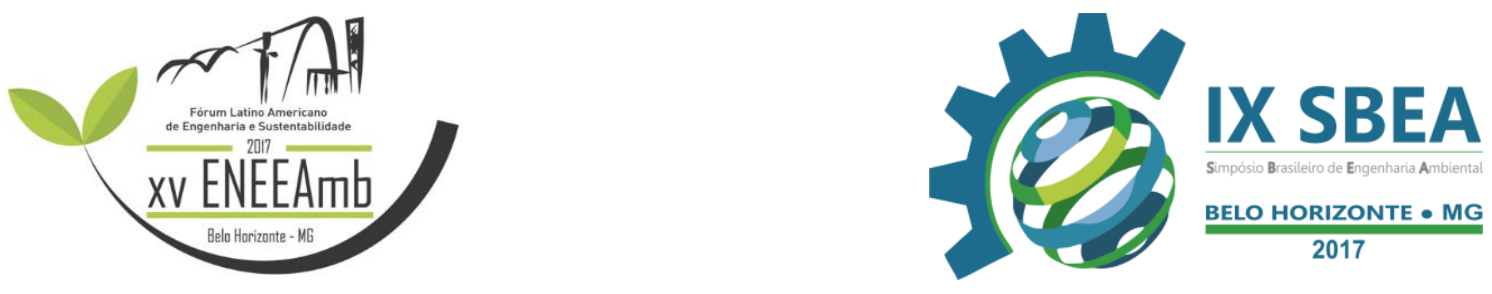

de incineração. As cinzas resultantes do procedimento, são submetidas a análise com o intuito de verificar-se o grau de periculosidade das mesmas. De acordo com o grau de risco, as cinzas podem ser encaminhadas para o aterro sanitário da própria empresa, ou em periculosidade extrema transportadas para a cidade de Brasília-DF. O responsável pelo gerenciamento dos resíduos do Hospital não informou a maneira de deslocamento destes resíduos até a capital nacional. Os responsáveis técnicos pelo Plano de Gerenciamento de Resíduos do Hospital deslocam-se para a sede da empresa terceirizada uma vez ao ano para averiguação de cumprimento de contrato.

\section{CONCLUSÃO}

A Unidade de Saúde cumpre, com as etapas básicas (coleta, segregação, acondicionamento, transporte interno, transporte externo e destinação final) exigidas pelo Plano de Gerenciamento de Resíduos de Serviço de Saúde, estando em consonância com a Resolução RDC No 306:2004. Entretanto, a etapa de tratamento de resíduos infectantes carece de informações quanto à forma de incineração dos resíduos.

Levando em consideração as características verificadas do gerenciamento dos resíduos de serviço de saúde no hopital, pode-se recomendar que a etapa de manejo pode ser realizada em horários que não apresentam circulação de pacientes e funcionários do Hospital, com o intuito de evitar possíveis contatos dos circulantes com os resíduos coletados.

\section{REFERÊNCIAS}

BRASIL. Resolução RDC n 306, de 7 de dezembro de 2004. Dispõe sobre o Regulamento Técnico para o gerenciamento de resíduos de serviços de saúde.

IDESP. Instituto de Desenvolvimento econômico, social e ambiental do Pará. Estatística Municipal: Paragominas. Belém, 2014. Disponível em: $<$ http://fapespa2.pa.gov.br/pdf/estatisticaMunicipal/pdf/Paragominas.pdf $>$. Acesso em 24 mar. 2016.

MARTINS, H. D.;et al. Mapeamento da cobertura do solo de Paragominas-PA com imagens de satélite de alta resolução: aplicações para o Cadastro Ambiental Rural (CAR). In: SIMPÓSIO BRASILEIRO DE SENSORIAMENTO REMOTO - SBSR, 16., 2013, Belém. Anais. Foz do Iguaçú: Inpe, 2013. p. 1283 - 1290. Disponível em: 

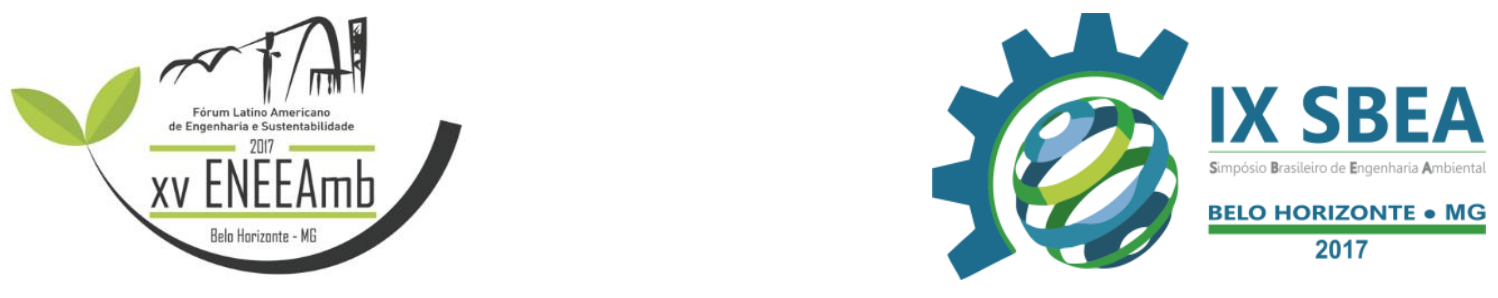

$<$ http://www.dsr.inpe.br/sbsr2013/files/p0598.pdf>. Acesso em: 23 ago. 2016.

NBR, ABNT. 10004:2004. Resíduos Sólidos: Classificação. Rio de janeiro: ABNT, 2004.

PEREIRA, J.T. N. Gerenciamento do Lixo Urbano: Aspectos Técnicos e Operacionais. Viçosa: Ufv, 2006. 163 p.

RIBEIRO, D. V.; MORELLI, M.R. Resíduos Sólidos: Problema ou Oportunidade. .Rio de Janeiro: Interciência, 2009. 135 p.

SCHNEIDER, V. E.; STEDILE, N. L. R.; BIGOLIN, M.; PAIZ, J. C. Sistema de Informações Gerenciais (SIG): ferramenta de monitoramento do gerenciamento de resíduos de serviços de saúde (RSS) e dos custos de tratamento. Revista de Gestão Ambiental e Sustentabilidade, São Paulo, v.2, n. 1, p. 166-188, mai. 2013, semestral. MOREIRA, I.G.; YAMANE, L.H.; SIMAN, R.R.; análise quali-quantitativa dos resíduos gerados em enfermaria do Hospital Santa Casa de Misericórdia de Vitória, Espírito Santo. Revista de Ciências Ambientais, Canoas, v.9, n.2, p. 23-35, 2015.

SCHNEIDER, V. E. et al. Manual de gerenciamento de resíduos sólidos em serviços de saúde. 2. ed. rev. e ampl. Caxias do Sul, RS: EDUCS, 2004. 